Article

\title{
"I Set the Camera on the Handle of My Dresser": Re-Matter-lalizing Social Media Visual Methods through a Case Study of Selfies
}

\author{
Katie Warfield \\ Journalism and Communication Studies, Kwantlen Polytechnic University, Surrey, BC V3W 2M8, Canada; \\ E-Mail: katie.warfield@kpu.ca
}

Submitted: 30 May 2017 | Accepted: 14 August 2017 | Published: 21 December 2017

\begin{abstract}
This article is a confession about research trouble and the start of a narrative of research rectification. I begin this article with a review of new materialist theory and methods broadly and specifically those that contribute insight into interviews and photo elicitation such as intra-views and posthuman visual methods. I then detail the research methodology I used for an empirical study conducted last year to look at what young women experience while taking selfies, or images of their face and body to be shared on social media. After this fairly procedural account, I return to my messy research notes and video recordings, and-rather than reread-I re-trace and re-matter-ialize one specific interview with one young woman using new materialist methods (intra-views and reading images horizontally) to reveal data that would otherwise not have been evidenced via my original humanist methods. Re-matter-ializing describes my process as a researcher re-visiting not only the discursive moments, but the affective encounters and the matter of the research assemblage; meaning I move beyond the spoken data to look at how the material-discursive-afffective assemblage or arrangment of the interview room, technologies of data recording, props in the room, and embodied interactions of the participants were entangled in and vital agents in the production of data. In conclusion I detail the benefits of a posthuman re-tracing: 1 ) an attentiveness to the complex human and non-human agents in a research assemblage, 2) a response-ability or ethical duty of researchers to not reduce the complexity of the phenomena they study, 3) the importance of affect in the research encounter especially in visual methods, and, 4) a questioning of the implicit assumption that-of all steps in a research program-methodology is the least malleable.
\end{abstract}

\section{Keywords}

intra-view; new materialism; photo elicitation; posthumanism; social media

Issue

This article is part of the issue "Visual Communication in the Age of Social Media: Conceptual, Theoretical and Methodological Challenges", edited by Uta Russmann (FHWien der WKW University of Applied Sciences for Management \& Communication, Austria) and Jakob Svensson (Malmö University, Sweden).

(C) 2017 by the author; licensee Cogitatio (Lisbon, Portugal). This article is licensed under a Creative Commons Attribution 4.0 International License (CC BY).

\section{Introduction}

I mostly take selfies for my boyfriend. I always take them in the same place in the privacy of my room. I set up the camera on a handle of my dresser that is just at the right angle like eye-level so it would be as if we were facing each other if we were together. (Kelly)

This quote is borrowed from one of four phenomenological interviews I conducted this past year with a group of young women who are self-described "avid selfie takers" meaning they take and share, per week via social media, at least three photos that reveal, to some degree, their body whether it is their face, a portion of their face, a portion of their body, or their whole body.

When I conducted this research I chose phenomenological interviews combined with photo elicitation, as I wanted to have the young women describe the embodied feelings and senses in and through the moment of taking these images. For two different papers I used a posthumanist framework of analysis often focusing on the work of Karen Barad. The methods functioned as a 
mode to get to the close lived experience of the young women in the phenomenon, but then when I began to reflect more broadly on my observational data and what was going on in the interview room, the humanist tradition of phenomenology revealed limitations. By marking the intimate embodied voice of the participant the exclusive unit of analysis, the method focused too heavily on language as data source. Phenomenology did permit me to think of my participants as intersubjective and relational with the world, however, the method continued to restrict and contract my data to narrative. Reflecting on Kelly's quote above in her own selfie-taking practice, and then reflecting on what I saw repeatedly in the interview room, I noticed that when the young women took their selfies, the shape and size of the interview room, the available props, the lighting, the technologies of self imaging, the technologies of data recording, the cellphones and available filters, and even the affective presence of me as the researcher in the room were all at once productive data and productive of data in the moment of research. Just as qualitative research describes interview data as both the analysis of discourse and its own discursive moment, what I saw was that visual research can be also both about matter and mattering-or considering the impact of the materiality of the research assemblage in the production of knowledge.

Upon this realization, I honestly recall thinking: "If only I'd just adopted a post-structural framework then I could focus more on coding and thematically grouping themes through words. If I'd done that, then this paper would be sooooo much easier to write!" But I didn't. And I'm glad I didn't. Thank goodness for pilots. This article is a confession about research troubles, an encouragement to sit with the trouble (Haraway, 2016), and the start of a narrative of research rectification.

I begin this article with a review of new materialist methods related to, and emerging from, the classic qualitative methods of interviews and photo elicitation: intraviews and posthuman visual methods.

I then detail the research methodology I used for my original study last year. After this fairly procedural account, I return to my original messy research notes, video recordings, and photos to provide a new materialist re-tracing (Mazzei \& McCoy, 2010) of my research, which permits us to see what could not be seen with phenomenological methods strictly, and also to reflect on moments of possibility and change in my furture plans for this project. I pull back and revisit my research at the level and unit of the research assemblage (Fox \& Alldred, 2014), where I'm not looking at any one specific entity but I'm looking at the intra-action (Barad, 2007) or entanglement of all the research entities (e.g. participants, research methodology, recording tools, data, researcher). In doing this, I am permitted to focus on, not only the discursive moments, but also, more inclusively, the material-discursive and affective data at work in the research assemblage. What becomes data sources, then are: the recorded words and images (discursive forces), the visual recording devices, cellphone camera, imaging filters, and lighting and the design of the room (material forces), and the affective and felt forces traded and exchanged both between me, the participants, and the non-human material elements, and which also viserally connect outside and beyond the specific research moment. In other words, I re-matter-ialize one specific interview, to show the "coming together of multiple forces in momentary alignment" (Kuntz \& Presnall, 2012, p. 740) and also to reveal data that would otherwise not have been evidenced with my original humanist methods. Paraphrasing Karen Barad, I include other forms of matter and thus make more things matter (Barad, 2007) in visual research of mobile-networked visual phenomena. Following Mazzei and McCoy (2010), I suggest that such a process of re-tracing encourages me as a researcher (and could encourage others) to reflect on: our situated practices, the forces of material habit in research inquiry, as well as the more expansive map of possibilities, issues, failures, and successes of a given method in practice.

\section{Literature Review}

The material or ontological turn has many names and forms: posthumanism, new materialism the postqualitative turn. Earlier mentions of posthumanism persist in the writings of gender and technology theorists like Katherine Hayles (How We Became Posthuman, 2010), and Donna Haraway's ironic Cyborg Manifesto (1991), and decolonizing theorists have argued that posthuman philosophies have existed as a core component of Indigenous knowledge for millenia (Sundberg, 2014; Todd, 2016). At the heart of posthumanism is a rethinking of anthropocentrism - or the Renaissance celebration and reification of the liberal human subject. Instead, as Juanita Sundberg explains, posthumanism as a diverse set of Anglo-European ideas, "refuses to treat the human as 1) ontologically given, [and] not the only actor of consequence, and 2) disembodied and autonomous, separate from the world of nature and animality" (Sundberg, 2014, p. 34). New Materialism, which often draws on the works of Gilles Deleuze, Felix Guattari, Bruno Latour, and Karen Barad, offers several common objectives: challenge the desire to seek cause and effect relationships within qualitative methods, challenge the dominance of representationalism in humanist theory and practice (Barad, 2007; Braidotti, 2013; Dolphijn \& van der Tuin, 2012), reject the Cartesian divide between mind and body (Barad, 2007), critique the linguistic turn's dominant emphasis on language at the expense of materiality (Barad, 2007) that could lead to "narrative seduction" (Chambers, 1984), reject positivism's tendency to simplify and generalize and critique the researcher's presumed-to-be removed position from their object of study and the research event itself (Barad, 2007).

In exchange or these themes, and when we look specifically at new materialist methods, theorists emphasize: the importance of discourse, matter, and affect in 
research methods. Rejecting reduction and simplificty, posthuman methods prefer more complex units of analysis like for Deleuze and Guattari the assemblage, and for Karen Barad, the phenomenon because these terms avoid a priori differentiation and delineation. Posthuman research begins with the multifaceted entanglement of material and discursive and affective forces in a given moment. The entitiy then, for instance the word or the image, does not pre-exist a priori its entanglement, rather it emerges from its entanglements through processes of naming and differentiating (Deleuze \& Guattari, 2014) or acts of agential cutting (Barad, 2007), which snip the complex tendrils of entanglment. It is through what Barad (2007) calls, these intra-actions-becoming through not interacting among-that objects and concepts are defined and constantly redefined out of their more naturally implicit entanglment within their material, discursive, and affective surroundings. This may include a coming together of bodies, space, place, technology, and non-human actors like objects (Latour, 2000; Salk, Latour, \& Woolgar, 2013).

\section{General Notes on a New Materialist Research Approach}

According to Deleuze and Guattari (2014), research is a machine "that links elements together to do things" (Deleuze \& Guattari, 2014, p. 4). The machine operates via a combination of disciplinary logics, situated reasoning, and genealogies of ways of thinking. In assessing any research initiative then, a singular linguistic unit of analysis from any one discursive moment in the process does not suffice. Instead posthuman methods attend to the research assemblage, or the heterogenous constellation comprising the "events to be researched, research tools such as questionnaires, interview schedules or other apparatus; recording and analysis technologies, computer software and hardware, theoretical frameworks and hypotheses, research literature and findings from previous studies, and of course researchers (Fox \& Alldred, 2014, p. 404). When we open the research assemblage to this unit, what is included is not only the individual bodies and specific units of language produced, but also the material arrangement of tools and setting (e.g. location, recording devices, and apparatuses), and also the impact of affect, feeling and sensation and the movement of affect within the phenomenon. When I use the term affect I know I enter into sticky territory because, if we believe Melissa Gregg and Gregg Seigworth (2010), affect is a term that "has no one single or generalizable theory" (p. 3). We can define affect to a degree by a process of elimination: whereas the discursive turn focused primarily on words traded in the research assemblage, and the material turn is interested in how matter, be it research apparatuses, tools, recording devises and other technologies influence the research assemblage, affect trades in the realm of "visceral forces beneath, alongside, or generally other than conscious knowing, vital forces insisting beyond emotion - that can serve to drive us toward movement, toward thought and extension, that can likewise suspend us (as if in neutral) across a barely registering accretion of force-relations, or that can even leave us overwhelmed by the world's apparent intractability" (Gregg \& Seigworth, 2010, p. 1) As such, and according to new materialist research, researchers should trace "affective economies that territorialize and de-territorialize the capacities of bodies, collectivities, and other relations within an assemblage" (p. 409). In other words what forces beyond the material and discursive flow and fluctuate in ways that enable or disable action within a research assemblage? In sum, then, when I explore and re-matter-ialize the research assemblage of the interviews I did last year, I revisit not just the recorded textual and visual data, but also the material environment of the interview setting, the discursive forces entangled therein, and the affective potencies that shape the empirical moment.

In the next section I introduce three specific new materialist methods that I layer on to the original research data to reveal material and affective data that otherwise would not have been evidenced with my original humanist research methods: posthuman re-tracing, the intraview and reading images horizontally.

\section{Re-Tracing the Interview}

What I'm doing in this article is a process of posthumanist re-tracing. I'm confessing to a moment of research uncertainty and opening myself up to, curiosity, creativity, and recification. In most posthuman methods, uncertainty guides the research process. Hillevi Lenz Taguchi discusses the notion of nomadic thinking and methods where researchers are encouraged to not root their ideas, methods, frameworks so deeply that they fail to look at the world around them from new perspectives. Hultman and Lenz Taguchi (2010) encourage researchers to remain nomadic or mobile, and to be pushed and pulled in different directions by the research but then to also be attentive and to make visible in their writing and publishing these affective forces upon their thinking.

When certainty guides a research program, then what emerges, according to Deleuze and Guattari, are tracings. Deleuze and Guattari use the term map to represent the natural compexity of the research assemblage. Tracings are the habitual normative marks of knowledge that emerge upon the naturally more expansive map, and tracings are often re-traced because of material and discursive habits of both knowledge production and research methodology practices. The world as examined and described by confident and certain researchers tends to trace and retrace the same lines in research assemblages as previous research before it even when new emergent data reveals itself. Tracings disregard difference and disjunction focusing more on repetition and commonality. Tracings reify theory and method above emiprical cracks and fissures. Ways of thinking, ways of 
seeing, and habits of practice encourage the researcher to arrange tools, analyze data, and write up results in predictable ways. In order to avoid research tracings, Mazzei and McCoy (2010) suggest, "that the tracing is put back on the map" (p. 505). What Mazzei and McCoy mean by this is that if mapping is the complete and implicit complexity of the research assemblage, and a tracing is a routing of an ossified research program, then by layering the tracing on the map, we can see the alignments and disjunctions between complexity and simplification between what is experienced in the moment and what is desired and/or habitual by the researcher and their research program. We see "impasses, blockages, incipient taproots, or points of structuration" (p. 507). By making visible our research tracings on maps, we take a step back as researchers and reveal the nuances and manufactured nature of our own research attempts. We reflect on our phenomenological experience, or material choices, our discursive influences, and our affectivelymotivated movements in the research assemblage in order to make visible the more expansive map of possibilities, issues, failures, and successes of a given method in practice. Thus the trace is placed back on the map, the method is checked against the situated moment, and the research method does not become reified when perhaps the phenomenon under study grows beyond the methodology's capacities. It is my hope that my process of re-tracing stands out as an effort to remain uncertain and "to interrupt knowledge production that maps easily onto taken-for-granted regimes of meaning" (Lather, 2007, p. 85).

\section{From Interview to Posthuman Intra-View}

The emphasis within qualitative interviews on coding (and more recently processing through digital analysis software) has both removed the words from the body of the participant, and the researcher from the ears and voice of the subject they are studying. Denzin (2010) goes so far as to suggest that the interview transcript acts as a mechanism of control that inscribes tacitly a representational epistemology or a focus on the surface or words and not the deeper meaning embodied by the subject at the moment of speaking. The intra-view attempts to contribute to the well known, and continuing debates concerning the reification of data via recorded words or transcripts, to flesh out the material, discursive and affective complexity of the topic under study, while also attending to the material, discursive, and affective moment of the interview itself and how these factors could impact the data produced in the interview moment.

Whereas inter-views (inter meaning between) see the method as a creation of meaning between two distinct entities (participant and interviewer) via the medium of representational words, the intra-view, a new materialist rethinking of the inter-view, replaces the prefix inter- with intra- meaning "within". In the intraview, meaning is not a production of words between two bounded participants, but rather, the intra-view is a deep and holistic coming together of multiple bodies and material-discursive-affective forces. The bodies of the participants which have resulted from their own distinct entanglements, genealogies, and histories, come together, in a specific research environment, via specific genealogically enshrined research methods guided by rooted epistemologies and ontologies, to intra-actively create a novel entanglement and research becoming. Kuntz and Presnall (2012) enumerate several tactics to intra-viewing: moving from script to sound, attending to embodied vibrations, and seeking out metaphors.

A move from script to sound occurs where the researcher attends to, not only the spoken words but also, the pauses, tones, inflections, glitches and mistakes in conversation. These markers highlight the affective, felt, and emotional moments in the encounter. Listening to the spaces in between attends to the affect behind and flowing through the discursive moment.

Intra-viewing also attends to what are called the embodied vibrations which mark where and when the body withdraws from conversation, or the text become distant and less intimate or equally proximate and increasingly intimate. These subtle changes also mark the affective proximity and distance of the researcher to the interviewee. In terms of working with visual data and photo elicitation, embodied vibrations can also mark the affective significance of a participant in relation to the nonhuman elements in the research assemblage like the interview room, recording tools, or prompting tools like photos for photo elicitation. For instance, I've tended to, in my own work with photo eliciation, treat certain photos with more care when, for instance, I see a participant cringe or hold tenuously or carefully an image. Not all images hold the same degree of affective significance as others and researchers need to learn to read the embodied vibrations that give insight into the significance of one image over another. Posthuman methods encourage researchers to be attentive to the embodied vibrations that arise between participants and the material components of the research assemblage.

Finally, intra-views also attend to the use of metaphors to describe experience which Neisser (2003) argues are creative spaces. Metaphors are phenomenological in nature and are moments where participants push the limits and habits of language to bring the medium of words closer to the lived and embodied and thus affective experience of a moment. Attending to the affective strength of words in an intra-view is key to attending to both the affective and discursive data in a research assemblage.

\section{From Visual Methods to Diffractive Readings}

Karen Hultman and Hillevi Lenz Taguchi (2010) have arguably made the most significant contributions not only to new materialism in educational research but also to new materialist influenced visual methods. In the next 
section I examine their methods of: 1) reading images horizontally and 2) Deleuzian difference.

Reading images horizontally challenges liberal humanist habits of seeing. Whereas we tend to focus on the human subject in, say, a photo we are analyzing, thus looking at the photo anthropocentrically and vertically, or top down, from researcher, down to the image, Taguchi encourages a positioning of the researcher on the edge of the photo where, we could imagine, the eye peaks just over the surface of the film. From this position, we move away from our habit of focusing on the human in the image, and instead see the manifold elements of the image, the varying colors and shapes, and the relationship between the elements of the image instead of, automatically, their distinction from one another. Here we see with equal weight the human and non-human elements of the image: the subjects, but also their context and surroundings, the time of day, the location, and other. We read the image as a material-discursivehuman-non-human entanglement. In my own work on social media, I've also decribed how peeking over the side of the image permits us to look at an image temporally as a snapshot of a material-discusive-affective moment in time and place, but also entangled with a material-discursive-affective past and possibly also with a material-discursive and affective future if, for instance we are talking about a socially mediated image that are often shared and find a new life online. The image then, turned and viewed sideways is a representation with material-discursive and affective tendrils that stretch and reach outward to an imagined furture and are connected to an entangled past which can provide rich insight into the specific photographic moment.

In assessing the image from this vantage, Taguchi suggests we search for Deleuzian "forms of difference" instead of difference as conceived by the humanist tradition. As mentioned, under the humanist tradition, entities are presumed to be a priori separate. Difference, then, is a positioning of one entity against, in comparison, and often in distinction from another. This form of difference is what Deleuze and Guattari call negative difference. A Deleuzian conception of difference starts from the more complex unit of the assemblage wherein connection is the a priori state of affairs. Difference, then is when the affective forces that shaped the assemblage and tend to shape assemblages in predictable ways, are challenged and made anew in creative ways. Thus difference in a Deleuzian sense is "productive difference"-difference that marks change, creativity, play, agency and newness.

\section{The Original Methodology}

I began the data collection with an interest in what young women actually experience when they take selfies. What are their thoughts and feelings while facing the camera, editing the images, and sharing the images online? My research questions then became: 1 ) how do you experience selfies? 2) what do you gain from creating selfies?

I developed a variation of photo elicitation (Harper, 2012; Knowles \& Sweetman, 2004) and in-depth interviews to explore the lived experiences, feelings, and beliefs of the participants (Groenewald, 2004; Hycner, 1985). I was particularly interested in the feelings that emerged in the real-time moment of image production. Douglas Harper (2012) discusses something akin to immediate photo-elicitation where the temporal gap between the image being taken and the subject reflecting on the image is minimized so as to reflect freshly on the feelings and experiences associated with a given moment in time. I arranged the recording apparatus, which I'll detail below, in a manner that allowed me to explore these proximate moments of reflection (Groenewald, 2004; Hycner, 1985).

\section{Data Generation and Findings}

Although I originally recruited and interviewed four young women, ${ }^{1}$ this article will focus on the research data of only one participant, Jackie. In a private interview room, I set up a digital video recorder on a desk and flipped the view-screen outward so the participant could see herself on the screen. I provided different lighting options (fluorescent overhead lights, lamps, and tripod mounted photo lighting) because I'd learned from workshops with young women and casual conversations that lighting was a key factor in good selfies. I then gave each young woman up to 10 minutes to prepare the room and camera, as she desired.

I started by asking each young woman a series of questions from an interview guide ${ }^{2}$ I had prepared that encouraged her to reflect on the phenomenon of taking selfies. These preliminary interviews lasted between 45 minutes and one hour each. I then asked the young women to take as many selfies as they wanted until they produced two images they felt were good enough to share on a social media platform. For the selfie-taking process, I asked each young woman to narrate freely and naturally her experience of taking, reviewing, editing and applying filters to her selfies (Hycner, 1985). Taking selfies is a discursively influenced practice ${ }^{3}$ and as such, they are typically taken in private locations (Warfield, 2015). It was this discovery that made me want to do the interviews in the privacy of a self-contained room at my university. It was also this that made me remove myself from the interview room when the young women took photos of themselves. Thus, I was out of the room, speaking with and watching the young women through Google chat as well as taking observational notes as they produced what

\footnotetext{
${ }^{1}$ For my original pilot research design, I recruited a sample size of four (recommended by Groenewald, 2004, and Hycner, 1985) young female avid selfies takers defined as people who had been taking selfies for more than two years, and who also take more than three selfies per week, and are also aged 18-30.

2 I provide some of the questions from the interview later in this article.

${ }^{3}$ The discursive treatment of selfies has been examined by several theorists including Anne Burns (2015), and Nancy Baym and Theresa Senft (2015).
} 
I asked them to judge as good enough selfies for distribution to some social media platform ${ }^{4}$ (Groenewald, 2004). Although Google chat was set up and I could see them, I turned my camera off so that I wasn't visible to them. I'd already adapted the material circumstances of my interview room based both of empirical data from some of my other empirical work.

\section{Reflection on the Methodology via Posthumanism}

As mentioned, posthuman methodologies enter into research from a position of uncertainty. Nothing is solid and the cracks and fissures in the research assemblage become the in-roads for new data collection, analysis and methodological adaptation. Instead of the mistakes, glitches and faults in the research are seen as marking simply the habitual boundaries and limitations of the research project, where "error becomes the limit" (Mazzei \& McCoy, 2010, p. 505). Instead of a limit, I highlight those moments as potential starting points for lines of flight-positive difference from the normative repetition of research procedures. Posthuman research, drawing on Patti Lather's work, "must shift the debate away from tired epistemological contests toward an examination of how a discipline works toward creating new phenomena" (Lather, 2007, p. 140).

\section{The Intra-Action of Jackie with Her Selfies}

Each of the four young women who came into the room slipped into the space with different levels of comfortsometimes quickly, sometimes awkwardly. For some of the participants the room didn't really matter...or I should say they seemed to be able to "master" the room, overcome its limitations quickly, as opposed to others. Jackie did not overcome the room easily. Her whole interview was a material, discursive, and affective battle with her surroundings.

Once Jackie enters the room, she immediately goes to work moving, adjusting, and arranging the lighting, chair, and background. ${ }^{5}$

$\mathrm{J}$ : "So I'm going to adjust the lighting because I don't want my face to look super bright" She works silently and takes a series of photos pausing for a minute after each one to look at the camera. In re-watching the interview, however, I tried to remain nomadic, avoid the habits of practice and seeing that humanist qualitative methods tacitly impose. Avoiding the occulocentrism of visual methods, I closed my eyes as the video played. I moved from script to sound and listened to the event: a chair moves, a synthetic shutter sound, a pause, a sigh, the light is relocated, the base sliding along the floor. No words or script was spoken, but the sounds indicated the rubbing together of body, space, technology, camera, and interview room. Were I to have limited my data to the transcript of the video recording, I would have missed all this. Opening my data to sound revealed the entanglement of the materiality of the room, with Jackie's body, with he affective sighs and awkward giggles, in the process of making the image. The sound was the material, discursive, and affective labour behind the image.

J: "I like the second one more because I like how the light hits my face...." She studies the photo a bit longer and then adds "I usually like it more when my cheek bones look prominent". She looks in the camera lens and touches her hand to her cheeks - first on one side and then on the other. She lifts the camera up again and sucks in her cheeks, again looking behind her for the location of the light and turning her body in relation to the light and how it looks on the screen of the camera.

$\mathrm{J}$ : "...and if there's sort of a shadow at my jaw line".

I ask her: "How do you achieve that? The jaw line?"

J: "Lighting". She pauses and looks at the screen again. "Angle". She moves the camera around again.

I'm amazed by this process. Every girl l've interviewed has developed a different relationship with the camera. Kayla, who I interviewed the day before, in the same room, and who has been taking selfies the longest ( 2 years), had no problem with this task. She pulled out her phone, snapped five photos and said that of those, three would be good enough to share on Instragram. For Jackie, she seems naturally to be able to toggle between an anthropocentric "habit of looking" (Hillevi) at the photo to a, maybe we can call it a techno-centric habit of seeing as she moves to the level of photographic glitches, lighting, angle, and image quality-discourses of self-presentation are revealed in both embodied presentation and technological manipulation.

But here Jackie is struggling. I'm sitting in a different room from her. In re-watching I remember what I was feeling well in this moment. And here I place my tracings on the map as a researcher in that moment; I at once knew what data I needed to be collected but I also remember thinking in that moment that words were not enough here. Other forces were at play. I was watching her on my desktop computer and I was feeling worried. Embarrassed a bit. I had started to really affectively sense the awkwardness of this research room set up for her. In my efforts to visually record these girls in the act of taking selfies, I manufactured a most false set-up for them to play in. Selfies don't happen in interview rooms. I knew this. I'd published papers on this. They happen in everyday life. But given what I wanted to learn-the experience in the moment of taking a selfie, how would I ever record this? I started to see what Jackie saw-the fluorescent lighting overhead is terrible. The light I brought in as a prop was warm but not bright enough. Maybe I should have rented some professional lighting equipment? But that would have definitely affected the outcomes of this research assemblage. The girls would see

\footnotetext{
${ }^{4}$ Although this was the quality of image I asked of them, I did not ask them to post the images online.

${ }^{5}$ I was unable to use visuals from the actual interview in this article first, for ethical reasons and assuring the confidentiality of my participants but second so that the analysis moves visual research beyond the visual to other sensory dimensions of data.
} 
themselves through the lighting of a professional magazine shoot. In any case, I start writing these thoughts on a scrap piece of paper on my desk to the side and thought: how can I at once let the girls take selfies of themselves as they naturally would in everyday practice and still record the rich visual data of them in the second to second process of taking the image and reflecting on it? Is it even possible? I write the word space on a piece of paper on my desk with three question marks after it. I return to Jackie:

J: "So I'm going to delete the first one. Should I delete them or should I keep them all first?" Jackie looks at the image on the screen of her phone and sticks out her lip.

I answer: “Ya, you can delete the ones you aren't going to keep and save the two you would be okay posting online and just tell me about the ones you are going to delete and why you are deleting them".

Jackie nods and there is a longer pause as she takes more photos always with an air of ambivalence. I find myself listening for sound instead of just attending to Jackie's words. She is quieter than the other girls. Reserved with words but her body speaks a lot. I try to attend to a diffractive method: producing the script but then listening to the space in-between and attentive to the bodily vibrations of the participant. When she came into the room her body was confident, as the interview goes on, she seems frustrated and the fatigued.

$\mathrm{J}$ : “See, this one I don't like it because my face looks really, really round", she swipes her thumb up on the screen to delete it "yup, nope". She takes another couple.

I ask: "And how would you achieve it not being so round?"

J: "Like this angle" Jackie holds the camera directly out in front of her. Her arms are outstretched. She continues, "...and from the front". She looks at the camera held out, smiles and then stops smiling. She looks at the camera, and then at me at the other side of the recording device, seemingly a bit frustrated, "So it is harder than I thought".

I say: "The room isn't ideal is it".

J: "Well, I mean the white background is good. I like that a lot. But the lighting, it just doesn't work".

There is a long pause and Jackie seems focused and determined in the space. She has stopped moving around the room and seems fixed in one spot. She is not taking many different and varied poses, but rather is working on micro permutations of one look.

When I think of the different modes of data collection, I am grateful of the layers I have: I have the photos the young women took. I have the video of the image production, and I have my observational notes. Were I to have just used the script of the immediate photo elliciation, I wouldn't be able to, as I am now, go back on and reflect on both the production of the image through the video, or my own reactions to the production of the video. The video becomes my recording of the research assemblage as a whole. I can listen not only to the sighs, grunts, and giggles that reflected the labour behind the image, but also reflect the affective relationship resulting from the entanglement of the image, the girl, and the less-that-perfect interview room.

J: "Okay, so I feel like I like this photo but I kind of want to edit it?"

I find myself happy at her saying that. I was worried that this whole process was a disaster but she seemed to develop determination and focus. And now she had a photo. I say "Ya, so tell me how are you going to edit it".

J: "I go to the app, and I open it, can you see it?" She opens the app and holds it up to the camera in the interview room so I can see it. "And I usually choose this filter. And then I go to fade and I just move that down a little bit". She is very fast with the filter app. Her finger slides across the image alternating between adjusting levels and clicking settings.

I ask: "Can you tell me a little bit, when you are looking at yourself in the camera but you haven't taken the image yet. What are you feeling or looking for?"

J: Shadows. "I try to look, like, I don't know how to explain it. ya, shadows. I like how this looks a little, I don't know how to...."

I ask, "You don't like shadows?"

J: "No, I do like shadows. I like seeing my cheek bones a bit". She uses the phone like a mirror and turns her head from side to side looking at her face. She turns her head a little more and looks at her ears. "And also I kind of like it when I show my ears".

Me: "Okay".

$\mathrm{J}:$ "Because I feel like my ears are my achievement because I've stretched them for more than 2 years".

In this moment I attend to this specific moment of positive difference, in the Deleuzian sense. Whereas up to this point Jackie had practiced habitual gendered modes of self-presentation: holding the camera at a high angle to diminish the size of her body, sucking in her cheeks, looking for shadows that made her face look slim, in this moment she collages certain standardly feminine presentational tropes with her non-stereotypically feminine stretched ear lobes. Using Deleuzian terms, here we see the familiar territorization of practices of gendered self-representation, but along side this is an affective line of flight-her stretched ears!-that shows the radical uniqueness of Jackie's affectively informed performance of the self. I wonder if perhaps the sparseness of the room brought her attention to focus on the details of her face. For Jackie, her ears aren't a defiance of beautyshe doesn't see them as intentionally not beautifulshe sees them as another form of beauty. They are a bodily representation of a non-normative presentation of femininity one marked by persistence, commitment, and acheivment. In a positive Deleuzian sense, she is not defying femininity in a binary sense, but laying out a new line of playful and creative flight, a new potential, a micro permutation, a new line of flight amidst infinite other lines. 


\section{Conclusion}

\subsection{Reflections}

I began with a select review of literature on new materialism, and research methods. I chose not to do a comprehensive analysis and instead focus on new methods that applied most directly to my original research design for my pilot study on selfies, which were phenomenological interviews and photo elicitation. These new materialist methods included: intra-views, reading images horizontally and using Deleuzian difference. I then detailed the research methodology I used for my original study last year. After this procedural account of the method, I return to my messy research notes, and reread only one interview using photo elicitation with one young woman, Jackie, to mine the research assemblage for data that would otherwise not be visible with my original humanist methods. I discuss how by focusing on the unit of the research assemblage, and not simply the transcripts, we move the usable data from a tight focus on the words (discourse) of the transcripts to more comprehensively include the discursive, material, and affective forces at work in the production of knowledge in visual research.

I begin by discussing the Deleuzian concept of tracing or the habitual movement through a research assemblage, which arises when a researcher adopts an attitude of certainty. Instead I discuss the approach of uncertainty where the researcher always remains open and attentive to moments in research where cracks, fissures and openings appear, which either challenge the limitation of the research method, or challenge the established knowledge of the phenomenon under study.

I discuss deeply the important of the material components of the research assemblage. I show how the research room itself, the lighting in the room, the cellphone camera, the glitches of the camera, or the available filters can all intra-act to both shape the moment of data collection and the knowledge that is produced in the research encounter.

I suggest throughout the article that visual methods move towards seeing photos in a posthuman sense as a snapshot of a material-discusrive-and affective moment. A strong attention to affect in visual research recognizes the embodied vibrations that can connect or disconnect a photo to a participant or perhaps bring up issues in the sharing of those images with researchers. I particularly apply the importance of the affective intensity of images to my participants and use the same measure of care they have with their images to my use of the images. Even if participants have signed photo releases, I recognize the affective variability of one photo to another and avoid using images in my work that seem to have strongly ambiguious affective relations to my participants. Or if I need to, I discuss individual photos with them, doubly confirming the consentual use of an image in my work.

There are many tools researchers of digital visual phenomena can take with them: digital images are entan- gled with their specific locations and environments and visual researchers need to be creative in finding ways to collect this nomadic visual data. Researchers need to be attentive to affect in image use and production since affect is often the measure of the degree of ethical duty a researcher has to the images being used. Researchers also need to remain uncertain and open to data gathering since new visual phenomena require a degree of curiosity and intrigue lest we automatically treat them in the same way as their analogue antecedents.

\subsection{Lessons for Future Visual Analysis}

There are many benefits to a posthuman approach to intra-views and new materialist informed photo elicitation, which I mention in the introduction and would like to take up here:

1) Attentiveness to the complexity human and nonhuman agents complicit in the production of the phenomenon and the research assemblage. By making the unit of analysis not a single or series of words, but rather the fundamental material-discursive complexity of phenomena, new materialist methods demand attentiveness to both human and non-human agents complicit in the production of the phenomenon.

2) A response-ability or an ethical duty researchers must have to not simplifying the complexity of the phenomena they study. Intra-active self-reflexivity forces researchers to acknowledge their role and influence in the research program. Nomadic thinking encourages researchers to break out of the habitual practices of qualitative methods and look at them anew. Nomadic thinking encourages a floating in the moment to see what the phenomenon offers unto itself rather than forcing the phenomenon to conform to the parameters of a specific method.

3) Listening to the sounds rather than reading the script of the research encounter-sounds resonated in my research design both through Jackie's body-the way she would sigh, seem hopeful, and then slouch or frown in disappointment. Sounds also resonated in relation to the non-human elements of the research assemblage: the insufficient design of the room, poor lighting, and impact of the camera. Listening for sounds and not just words, adjusts data collection to incorporate affective material and discursive data sources.

4) A reminder that, methodology seems to be the stage, which is the least malleable, least questioned of the stages in a research design. Methodologies are not a limited set of perfect tools but systems of knowledge making that are themselves designed upon worldviews and ontologies of a given moment in time and a given genealogy of thinking. When we dare to shake up methodologies and contest their reification, we keep research methods current and proximate to the mutable nature of the human experience.

I would like to finish by providing one last reflection on my research assemblage. I mentioned at the start that 
the interview I drew on here was part of a pilot study for future work on young women and digital self-imaging practices. I'd like to speak briefly of my current work on this project. I sat for a long time with the methodological issues I've pointed out in this project: how can I both be with the young women but not be present while they photo themselves? How can I also have the young women photograph themselves while also permitting the photos to take place in more natural environments? I'm grateful to be living in a time of mobile app development and technological innovation. I'm presently working with a user-interface company to use one of their apps, originally designed to run behind an existing app to visually capture how users use an app so as to improve the interface design. I'm presently working with my ethics board, and the app company, to use the interface to record my participants while they take photos of themselves to be shared on social media. How this would work is the app runs invisibly behind a social media platform's interface and my participants can turn on the app before they take photos. They would live record themselves photographing themselves in their specific locations and I would be able to watch them, and talk with them, on my computer at home in the live process of taking these videos. In short, it would be reproducing the set up I had for my pilot but the desk mounted video camera I used in my pilot would be swallowed invisibly into a background-running app on the cellphone itself while the young women weren't restricted to the, as we've established, terribly equipped interview room. I suspect there will be glitches. I am attentive to the ethics hurdles that will need to be cautiously worked through, but I'm excited about keeping visual methods fresh, novel, and creative, while also close to changing human experiences especially when it comes to our everyday uses of mobile imaging technologies.

\section{Acknowledgments}

I would like to thank the participants who worked tirlessly with me and who ended up teaching me how to do better research. I'd also like to thank Esme and Sebastien for always remind me to remain creative and playful even (or perhaps especially) when it comes to grown up work. And thank you to $D$ for teaching me the meaning of entanglement.

\section{Conflict of Interests}

The author declares no conflict of interests.

\section{References}

Barad, K. (2007). Meeting the universe halfway (1st ed.). Durham, NC: Duke University Press.

Baym, N., \& Senft, T. (2015). What does the selfie say? Investigating a global phenomenon. International Journal of Communication, 9, 1588-1606.
Braidotti. (2013). The posthuman (1st ed.). Oxford: Polity Press.

Burns, A. (2015). Self(ie)-discipline: Social regulation as enacted through the discussion of photographic practice. International Journal of Communication, 9, 1716-1733.

Chambers, R. (1984). Story and situation (1st ed.). Minneapolis, MN: University of Minnesota Press.

Deleuze, G., \& Guattari, F. (2014). A thousand plateaus (1st ed.). London: Bloomsbury Academic.

Denzin, N. (2010). The qualitative manifesto (1st ed.). Walnut Creek, CA: West Coast Books.

Dolphijn, R., \& Tuin, I. (2012). New materialism (1st ed.). Ann Arbor, MI: Open Humanities Press.

Fox, N., \& Alldred, P. (2014). New materialist social inquiry: Designs, methods and the researchassemblage. International Journal of Social Research Methodology, 18(4), 399-414.

Gregg, M., \& Seigworth, G. (2010). The affect studies reader. Durham, NC: Duke University Press.

Groenewald, T. (2004). A phenomenological research design illustrated. International Journal of Qualitative Methods, 3(1), 42-55.

Haraway, D. (1991). Cyborg manifesto. In D. Haraway (Ed.), Simians, cyborgs, and women (pp. 149-181). New York, NY: Routledge.

Haraway, D. (2016). Staying with the trouble: Making kin in the Chthulucene. Durham, NC: Duke University Press.

Harper, D. (2012). Visual sociology (1st ed.). London: Routledge.

Hayles, N. (2010). How we became posthuman. Chicago, IL: University of Chicago Press.

Hultman, K., \& Lenz Taguchi, H. (2010). Challenging anthropocentric analysis of visual data: A relational materialist methodological approach to educational research. International Journal of Qualitative Studies in Education, 23(5), 525-542.

Hycner, R. (1985). Some guidelines for the phenomenological analysis of interview data. Human Studies, 8(3), 279-303.

Knowles, C., \& Sweetman, P. (2004). Picturing the social landscape (1st ed.). London: Routledge, Taylor \& Francis Group.

Kuntz, A., \& Presnall, M. (2012). Wandering the tactical. Qualitative Inquiry, 18(9), 732-744.

Lather, P. (2007). Getting lost: Feminist efforts toward a double(d) science. Albany, NY: State University of New York Press.

Latour, B. (2000). We have never been modern (1st ed.). Essex: Pearson Education.

Mazzei, L., \& McCoy, K. (2010). Thinking with Deleuze in qualitative research. International Journal of Qualitative Studies in Education, 23(5), 503-509. doi:10.1080/09518398.2010.500634

Neisser, J. (2003). The swaying form: Imagination, metaphor, embodiment. Phenomenology and the Cognitive Sciences, 2, 27-53. 
Salk, J., Latour, B., \& Woolgar, S. (2013). Laboratory life (1st ed.). Princeton, NJ: Princeton University Press.

Sundberg, J. (2014). Decolonizing posthumanist geographies. Cultural Geographies, 21(1), 33-47.

Todd, Z. (2016). An Indigenous feminist's take on the ontological turn: 'Ontology' is just another word for colonialism. Journal of Historical Sociology, 29(1), 4-22.

Warfield, K. (2015). The model, The \#realme, and the selfconscious thespian. The International Journal of the Image, 6(2), 1-16.

\section{About the Author}

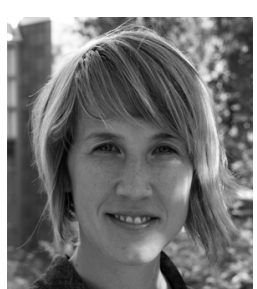

Katie Warfield is faculty in the Department of Journalism and Communication at Kwantlen Polytechnic University, and Director of the Visual Media Workshop. Her recent writings have appeared in Social Media + Society, Feminist Media Studies, Language and Literacy, and Feminist Issues, $6^{\text {th }}$ ed. by Pearson Education. She teaches classes in communication theory, popular culture, discourse theory, media and diversity, and social media. Her research is located at the intersection of post-phenomenology, new materialism, digital literacy, and gender theory. 